\title{
Monitoramento da qualidade da água tratada por sistema de desfluoretação de águas subterrâneas do campus da Universidade de Santa Cruz do Sul (UNISC), cidade de Santa Cruz do Sul, RS, Brasil
}

\author{
Cristiane Pappis ${ }^{1}$ \\ Luiza Baumann ${ }^{1}$ \\ Gisele Steil Rodrigues ${ }^{1}$ \\ Natália Bechi Maurer ${ }^{1}$ \\ Ronaldo Bastos dos Santos ${ }^{1}$ \\ Eduardo Alcayaga Lobo ${ }^{2}$ \\ Adilson Ben da Costa
}

\section{RESUMO}

O consumo da água com níveis de flúor acima do permitido pela Portaria $\mathrm{n}^{\mathrm{o}}$ 2914/2011 do Ministério da Saúde $\left(1,5 \mathrm{mg} \mathrm{L}^{-1}\right)$, é um dos principais fatores que levam à fluorose dental, principalmente em comunidades mais distantes, onde o acesso a água potável de boa qualidade é restrito. Neste contexto, este trabalho teve como objetivo avaliar a eficiência do carvão ativado de osso bovino (capacidade de adsorção de $1000 \mathrm{mg} \mathrm{g}^{-1}$ ), na adsorção de íons fluoreto de águas subterrâneas que são usadas para o abastecimento público. Amostras da água de poços artesianos localizados no campus da UNISC com uma concentração de fluoretos entre 2,3 e $3,4 \mathrm{mg} \mathrm{L}^{-1}$ foram coletadas e analisadas semanalmente, considerando as seguintes variáveis: condutividade elétrica, $\mathrm{pH}$, turbidez, e seus fluoretos. Os resultados indicaram que os cinco filtros foram altamente eficientes para remover parcialmente o flúor, tratando em média $15.398 \pm 3.487$ litros de água (Coeficiente de Variação, CV=22,6\%), dentro do especificado pela portaria $n^{\circ} 2914 / 2011$, a qual determina que a concentração de íons fluoretos na água para o consumo humano seja menor ou igual a $1,5 \mathrm{mg} \mathrm{L}^{-1}$. Desta forma, provamos a eficiência do carvão ativado de osso na adsorção dos íons fluoretos da água, destacando que o sistema de desfluoretação pode ser utilizado para uso coletivo, tanto em escolas como universidades.

Palavras-chave: Desfluoretação. Carvão Ativado de Osso. Qualidade da Água. Consumo Humano. Fluorose dental.

\begin{abstract}
The water consumption with fluoride levels above the maximum allowed by resolution $\mathrm{n}^{\mathrm{o}} 2914 / 2011$ of the Health Ministry $\left(1.5 \mathrm{mg} \mathrm{L}^{-1}\right)$ is one of the main factors that lead to dental fluorosis, especially in more distant communities where the access to water of good quality is restricted. In this context, the research aimed at evaluate the activated bone char (adsorption capacity of $1000 \mathrm{mg} \mathrm{g}^{-1}$ ) efficiency to remove the fluoride ions from groundwaters used for human consumption, by using the adsorption method that utilize filters with transparent polyethylene covering of high density. Waters samples from the artesian wells located in the campus of UNISC with a fluoride concentration of 2,3 and $3,4 \mathrm{mg} \mathrm{L}^{-1}$

\footnotetext{
${ }^{1}$ Alunos do curso de Química Industrial da Universidade de Santa Cruz do Sul.

${ }^{2}$ Professor do Departamento de Biologia e Farmácia na Universidade de Santa Cruz do Sul.

${ }^{3}$ Professor do Departamento de Biologia e Farmácia na Universidade de Santa Cruz do Sul. <adilson@unisc.br >
} 
were collected and analyzed weekly, considering the following variables: electrical conductivity, $\mathrm{pH}$, turbidity and fluorides. The results indicated that the five Poly Glass ${ }^{\circledR}$ filters were highly efficient for partially fluoride removing, treated in average $15.398 \pm 3.487$ liters of water (Coefficient of variation, $\mathrm{CV}=22,6 \%$ ), within the specification of resolution $\mathrm{n}^{\circ}$ $2914 / 2011$, which indicate a fluoride concentration in drinking waters up to $1.5 \mathrm{mg} \mathrm{L}^{-1}$. In this way, we proved the activated bone char efficiency for water fluoride ions adsorption, highlighting that this defluoridation system can be utilizes for collective use, both in schools and universities

Keywords: Defluoridation. Activated Bone Char. Water quality. Drinking Waters. Dental fluorosis.

\section{INTRODUÇÃO}

A água é um dos bens mais importantes para a humanidade, sendo elemento essencial pra a subsistência e manutenção da vida. Contudo, há um número significativo de pessoas que não possuem o acesso a água potável de boa qualidade, principalmente no Brasil, um país com cerca de 200 milhões de habitantes (IBGE, 2016), onde $45 \%$ da população não tem acesso ao serviço de água tratada (BRANCO, 2008).

Muitos fatores levam ao abastecimento desigual de água potável para a população, como em cidades do interior do Rio Grande do Sul, pois o abastecimento muitas vezes ocorre somente na área urbana, fazendo com que muitas localidades da zona rural sejam abastecidas por poços artesianos ou através das chamadas "sociedades hídricas". Esse fator também ocorre em grandes cidades, onde locais que demandam uma grande quantidade de água por dia, como em escolas ou universidades, não conseguem ser abastecidas pelas companhias distribuidoras de água, e acabam construindo poços artesianos para o abastecimento de água.

Segundo Lobo, Costa e Kirst (2000), em seus estudos realizados entre 1997 e 1999, constataram que nos Vales do Rio Pardo e Taquari, RS, 7\% das águas subterrâneas possuem excesso de íons fluoreto, o que por sua vez vem ocasionando uma patologia denominada fluorose dental, provocada pela ingestão crônica de flúor sobre o órgão do esmalte do dente, sendo que sua gravidade depende da dose ingerida, duração de exposição e tempo de ingestão (FLORES, 2010). A fluorose dental é uma anomalia cujas características vão desde finas linhas brancas cruzando os dentes em forma de traços, até várias formas de erosão. Os efeitos dependem da concentração e tempo de exposição ao fluoreto durante a infância no período de formação dos dentes permanentes (RIBEIRO, 2011).

No Brasil a primeira cidade que implantou o sistema de fluoretação da água foi no Baixo Gandu em 1953, situada na microrregião de Colatina Espírito Santo. (FREIRE; EMMERICH, 2003). O Rio Grande do Sul foi o primeiro Estado brasileiro onde se 
estabeleceu mediante lei, em 18 de junho de 1957, a obrigatoriedade da fluoretação das águas de abastecimento público (PIRES et al,. 1989). A fluoretação da água subterrânea de abastecimento público pode ser conceituada como um dos melhores critérios de saúde pública do mundo, pois é considerado um método de grande abrangência, podendo beneficiar todos os grupos socioeconômicos e mesmo assim apresentar uma excelente relação custo-benefício (BUZALAF, 2008).

Mariappan (2001) agrupou as técnicas de desfluorertação nas seguintes categorias: Adsorção, Troca Iônica, Precipitação, Eletroquímica e Membranas. Dentre tantas técnicas, a Associação Americana dos serviços de água (AWWA) considera como alternativas à alumina ativada (AA) e osmose reversa (OR) as tecnologias ou métodos da eletrodiálise (ED), eletrodiálise reversa (EDR), carvão de osso (CO) e destilação.

O carvão ativado de osso bovino é um material permeável de origem animal, sendo considerado um dos mais poderosos adsorventes conhecidos. Sua principal característica, e que o define, é a grande área superficial interna desenvolvida durante a ativação, formada por milhares de poros, classificados em: micro, meso e macro poros (BONECHAR- Carvão Ativado do Brasil Ltda., 2014). Segundo Ribeiro (2011), o carvão de osso é composto aproximadamente de até $80 \%$ de fosfato tricálcio ou hidroxiapatita $\left(\mathrm{Ca}_{10}\left(\mathrm{PO}_{4}\right)_{6}(\mathrm{OH})_{2}\right), 10 \%$ de carbono de cálcio. O carvão de ossos bovinos tem notável capacidade de remover flúor de águas, pois a rede cristalina do carvão de osso atua como um trocados aniônico e tem especial preferência por fluoretos.

A Portaria $n^{\circ} 2914$ de 12 de dezembro de 2011 do Ministério da Saúde (Brasil, 2011), estabelece que a água pode ser considerada potável quando atende aos parâmetros químicos, físicos, microbiológicos e radioativos para o consumo do ser humano, prevendo que os níveis de íons fluoreto não devem passar de $1,5 \mathrm{mg} \mathrm{L}^{-1}$.

Sistemas de desfluoretação de águas subterrâneas têm sido propostos na literatura e um deles é o sistema que utiliza como meio adsorvente o carvão ativado de osso (COSTA et al., 2008). Em seus estudos (KUMAR et al., 2010) aplicou o uso de nanotecnologia na elaboração de nano partículas com alumínio e carvão na remoção de íon fluoretos. O carvão ativado de osso bovino é um material permeável de origem animal, sendo considerado um dos mais poderosos adsorventes conhecidos.

Neste contexto, com a finalidade de contribuir para a erradicação da fluorose dentária, o objetivo deste trabalho foi avaliar a eficiência do carvão ativado de osso bovino na remoção de íons fluoreto de águas subterrâneas que são usadas para o abastecimento público, pelo método de adsorção. 


\section{MATERIAL E MÉTODOS}

No desenvolvimento desse estudo foi selecionado como meio adsorvente o carvão ativado de osso produzido pela Indústria Bonechar - Carvão Ativado do Brasil Ltda. (Maringá, PR). Como fonte de água foi utilizada a água de abastecimento do campus da Universidade de Santa Cruz do Sul (UNISC), RS, que apresenta concentração de íons fluoreto entre 2,3 e 3,4 $\mathrm{mg} \mathrm{L}^{-1}$. Ao todo foram instalados cinco filtros junto aos bebedouros localizados nos blocos 08 e 13 da UNISC. As Figuras 1 e 2 ilustram os cinco filtros de água instalados e seus componentes, destacando um tanque (filtro) Poly Glass ${ }^{\circledR}$ com revestimento de polietileno transparente de alta densidade, preenchido com $6 \mathrm{~kg}$ de carvão ativado de osso de diâmetro da partícula de 20 x 60 mesh, e um filtro auxiliar de fibra de celulose.

Figura 1. Sistemas de filtração por adsorção em filtros instalados nos bebedouros localizados nos blocos 08 e 13 da UNISC.

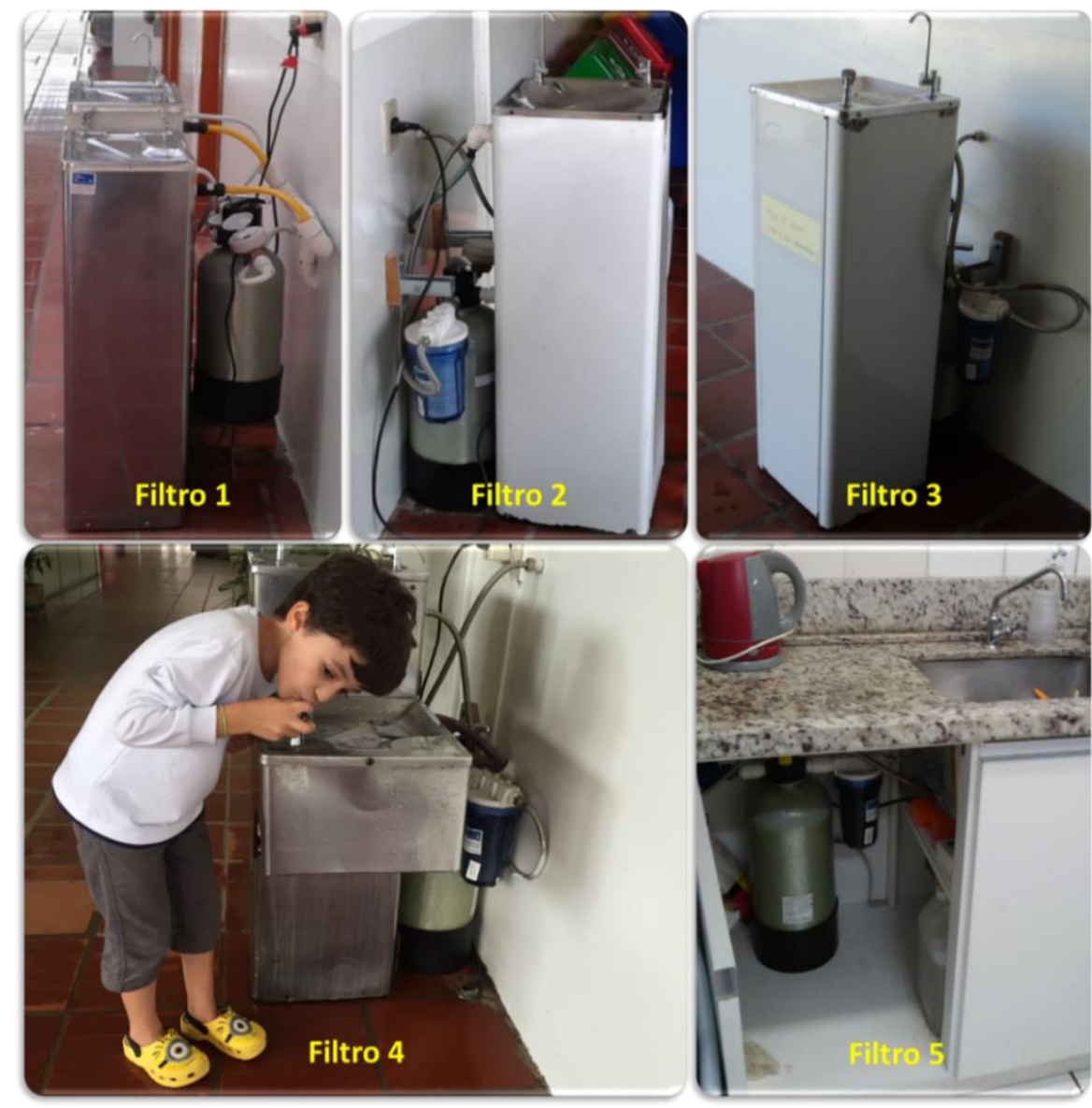

Fonte: Autores, (2017). 


\section{Figura 2. Funcionamento interno do filtro.}

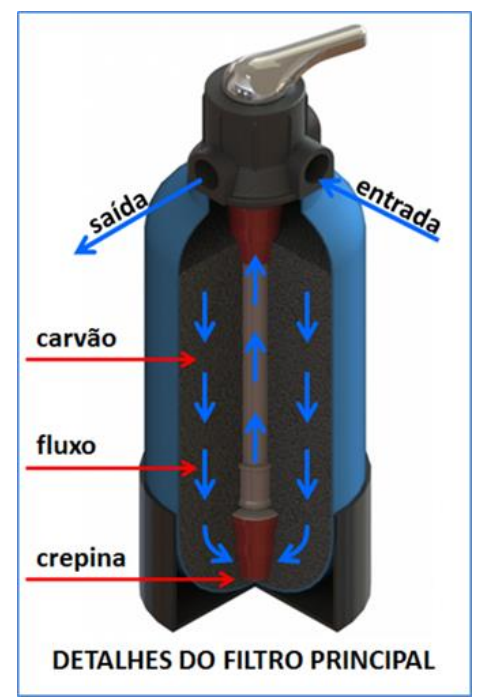

Fonte: Autores, (2017).

O processo de filtração acontece pelo princípio de adsorção, assim a água bruta (água subterrânea) ingressa no sistema passando pelo hidrômetro, chegando ao filtro de carvão ativado de osso (tanque Poly Glass $\left.{ }^{\circledR}\right)$. No filtro, o fluoreto contido na água é adsorvido pelo fase estacionária, resultando numa água tratada, com baixa concentração de fluoreto. Antes de sair do sistema a água passa por um filtro de fibra de celulose de $5 \mu \mathrm{m}$, que tem a função de remover materiais particulados eventualmente desprendidos do carvão ativado.

No início do processo o sistema de filtração foi purgado com água, ou seja os primeiro 50 litros de água filtrada foram descartados, servindo para a remoção de extraíveis e materiais particulados do carvão ativado. Iniciando o processo de filtração, a concentração de fluoreto na água tratada e bruta foi monitorada semanalmente, permitindo identificar a eficiência do processo de desfluoretação por adsorção e o instante de saturação do carvão ativado. A saturação completa da fase estacionária é identificada no instante em que a concentração de fluoreto na água tratada se iguala ao da água bruta. Com a saturação do carvão ativado de osso ocorre a posterior troca da fase estacionária reiniciando todo o processo novamente.

Durante o procedimento de filtração por adsorção foram avaliados semanalmente os seguintes parâmetros para todos os filtros em operação, tanto para a água tratada como para a água bruta: $\mathrm{pH}$, turbidez, condutividade elétrica e concentração de fluoreto. As metodologias analíticas utilizadas na coleta e as determinações físicas e químicas das amostras foram executadas segundo as normas descritas em (APHA, 2005). 
Para avaliar a eficiência do meio adsorvente, em termos de capacidade de adsorção, foi utilizada a equação descrita por Costa et al. (2013), a qual foi aplicada ao primeiro ciclo de desfluoretação de cada filtro.

$$
Q=\frac{\sum\left(C_{i}-C_{f}\right) \cdot V_{a t}}{m}
$$

Onde: $\mathrm{Ci}=$ concentração inicial $\left(\mathrm{mgL}^{-1}\right), \mathrm{Ci}=$ concentração final $\left(\mathrm{mgL}^{-1}\right)$, Vat $=$ volume de água tratada (L) e m = massa de carvão ativado de osso (kg).

\section{RESULTADOS E DISCUSÃO}

A Tabela 1 apresenta os resultados obtidos do monitoramento dos parâmetros fluoreto, $\mathrm{pH}$, condutividade elétrica e turbidez, indicando os valores médios e seus respectivos desvios-padrão, juntamente com o número de amostras analisadas. De acordo com os resultados obtidos, observa-se que as variáveis $\mathrm{pH}$, condutividade elétrica e turbidez não indicaram alterações expressivas a ponto de comprometer a potabilidade da água, permanecendo dentro dos padrões de potabilidade determinados pela Portaria $\mathrm{n}^{\mathbf{o}} 2914$ (BRASIL, 2011), a qual prevê que o pH da água esteja entre 6,0 e 9,5 e o valor da turbidez não ultrapasse 5,0 NTU. Já a condutividade elétrica não possui um limite estabelecido pelo Ministério da Saúde. 
Tabela 1. Resultados do monitoramento dos parâmetros fluoretos, pH, condutividade elétrica e turbidez da água subterrânea tratada pelo sistema de desfluoretação (media \pm desvio-padrão (tamanho amostra, $n$ ).

\begin{tabular}{|c|c|c|c|c|c|}
\hline Informações & F1 & $\mathrm{F} 2$ & F3 & $\mathrm{F} 4$ & F5 \\
\hline Fluoreto na água bruta, $\mathrm{mgL}^{-1}$ & $2,7 \pm 0,4(65)$ & $\begin{array}{l}3,0 \pm 0,4 \\
(64)\end{array}$ & $3,0 \pm 0,4(64)$ & $3,0 \pm 0,4(65)$ & $3,0 \pm 0,4(55)$ \\
\hline$\underset{1}{\text { Fluoreto na água tratada, } \mathrm{mgL}^{-}}$ & $1,3 \pm 0,6(65)$ & $\begin{array}{l}0,4 \pm 0,6 \\
(64)\end{array}$ & $0,3 \pm 0,7(64)$ & $1,0 \pm 1,1(65)$ & $1,9 \pm 1,2(55)$ \\
\hline $\mathrm{pH}$ na água bruta & $8,9 \pm 0,2(65)$ & $8,8 \pm 0,3(64)$ & $8,8 \pm 0,3(64)$ & $8,8 \pm 0,3(65)$ & $8,8 \pm 0,3(55)$ \\
\hline $\mathrm{pH}$ na água tratada & $8,8 \pm 0,3(65)$ & $8,8 \pm 0,3(64)$ & $8,8 \pm 0,3(64)$ & $8,8 \pm 0,2(65)$ & $8,7 \pm 0,4(55)$ \\
\hline $\begin{array}{l}\text { Condutividade Elétrica na água } \\
\text { bruta, } \mathrm{uS} / \mathrm{cm}^{2}\end{array}$ & $\begin{array}{l}563,1 \pm 94,7 \\
(65)\end{array}$ & $\begin{array}{l}587,3 \pm 67,0 \\
(64)\end{array}$ & $\begin{array}{l}585,5 \pm 66,2 \\
(64)\end{array}$ & $\begin{array}{l}586,9 \pm 66,6 \\
(65)\end{array}$ & $\begin{array}{l}587,9 \pm 66,6 \\
(55)\end{array}$ \\
\hline $\begin{array}{l}\text { Condutividade Elétrica na água } \\
\text { tratada, } \mathrm{uS} / \mathrm{cm}^{2}\end{array}$ & $\begin{array}{l}571,5 \pm 59,0 \\
(65)\end{array}$ & $\begin{array}{l}598,6 \pm 132,5 \\
(64)\end{array}$ & $\begin{array}{l}595,8 \pm 80,8 \\
(64)\end{array}$ & $\begin{array}{l}588,0 \pm 64,4 \\
(65)\end{array}$ & $\begin{array}{l}601,1 \pm 69,3 \\
(55)\end{array}$ \\
\hline Turbidez na água bruta, NTU & $<0,1(65)$ & $<0,1(64)$ & $<0,1(64)$ & $<0,1(65)$ & $<0,1(55)$ \\
\hline Turbidez na água tratada, NTU & $<0,1(65)$ & $<0,1(64)$ & $<0,1(64)$ & $<0,1(65)$ & $<0,1(55)$ \\
\hline
\end{tabular}

Fonte: Autores, (2017).

A Figura 3 apresenta os resultados obtidos no monitoramento na concentração de fluoretos na água subterrânea antes e após o tratamento pelos sistemas de adsorção nos filtros $1,2,3,4$ e 5, respectivamente.

O Filtro 1 tratou ao todo 16.694 litros de água. O filtro começou a operar com uma concentração de fluoreto na água bruta de $2,6 \mathrm{mg} \mathrm{L}^{-1}$, enquanto que a água tratada iniciou com valores próximos a zero, apresentando uma elevação gradual até atingir o limite de 1,5 $\mathrm{mg} \mathrm{L}^{-1}$, em 3.029 litros de água. Ao atingir 3.686 litros de água tratada, a concentração de fluoreto tornou-se equivalente ao da água bruta, indicando a saturação completa do sistema de desfluoretação, tendo havido a substituição do carvão ativado de osso, e iniciado um novo ciclo de tratamento. Posteriormente, em 11.435 litros, ocorreu novamente a saturação do carvão. 
Figura 3. Resultados do monitoramento da concentração de fluoretos da água subterrânea tratada pelo sistema de desfluoretação (Filtros 1, 2, 3, 4 e 5).

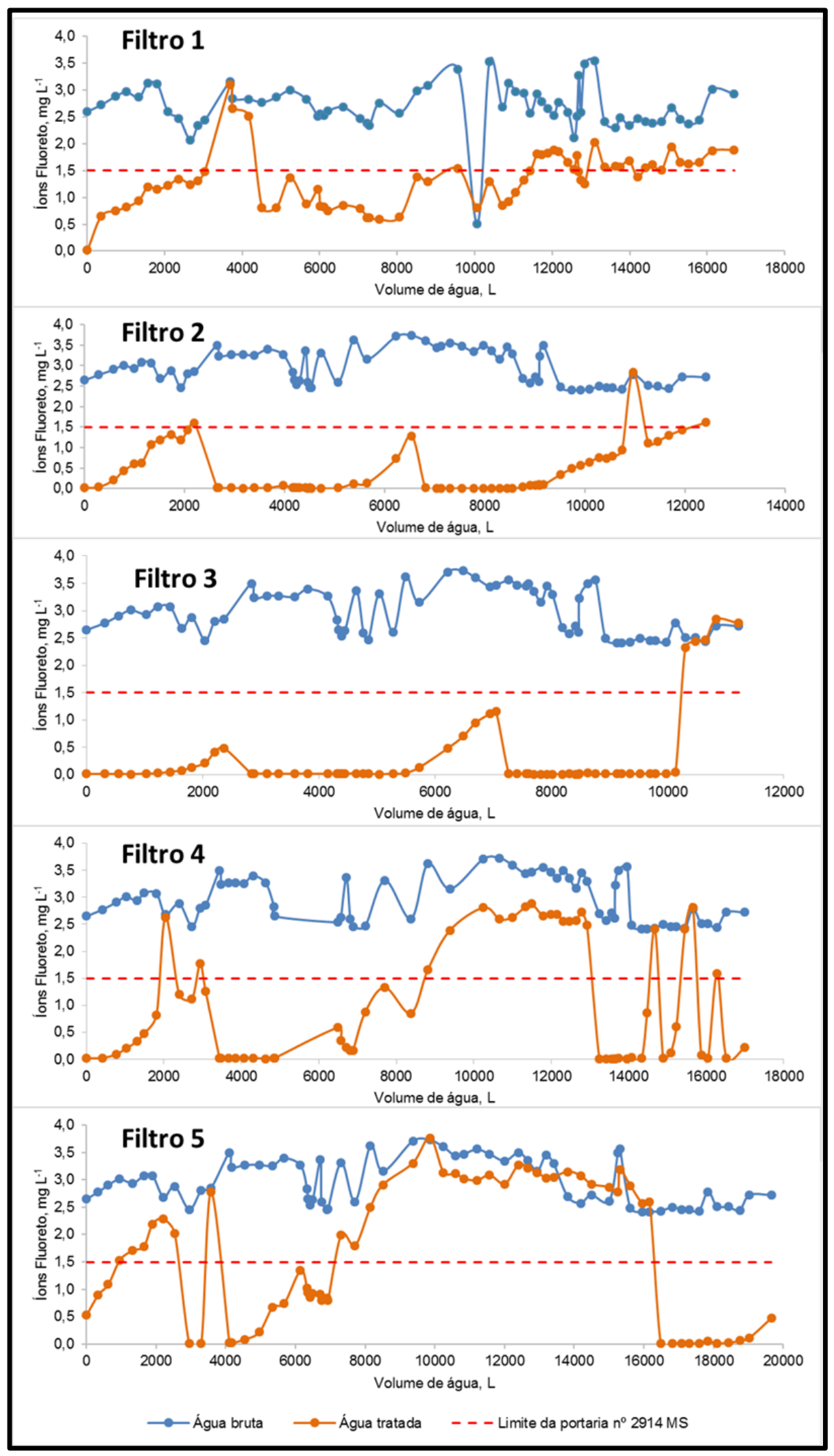

Fonte: Autores, (2017). 
Já o Filtro 2, tratou 12.418 litros de água. Este filtro iniciou a operação com uma concentração de fluoreto na água bruta de $2,6 \mathrm{mg} \mathrm{L}^{-1}$, enquanto que a água tratada iniciou com valores próximos a zero, evidenciando uma elevação gradual até atingir o limite de 1,5 $\mathrm{mg} \mathrm{L}^{-1}$, em 2.197 litros de água. Logo após, foi feita a troca do carvão, iniciando um novo ciclo de tratamento. É importante destacar que ao tratar 10.957 litros de água, a concentração de fluoreto na água tratada apresentou um resultado espúrio, similar ao da água bruta. Isto ocorreu por problemas de curto circuito na válvula principal do sistema, que foi imediatamente contornado.

No Filtro 3 foram tratados 11.225 litros de água, sendo que o sistema apresentou uma boa eficiência, apresentando resultados adequados ao limite estabelecido pela Portaria $\mathrm{n}^{\circ} 2914$ (BRASIL, 2011). Da mesma forma, o Filtro 4 também apresentou uma boa eficiência na remoção do flúor, tratando 16.998 litros de água. Cabe destacar que o sistema continuou em operação sem a troca da fase estacionária, para melhor compreender a eficiência do carvão ativado. Por fim, o Filtro 5 tratou aproximadamente 19.653 litros de água, apresentando uma boa eficiência na remoção do flúor. Os pontos em que as amostras passam do limite estabelecido correspondem ao local em que o filtro está localizado, onde se utiliza mais água em menos tempo.

Através dos resultados obtidos nos 5 filtros foi possível confirmar a alta eficiência do carvão ativado de osso bovino na remoção de fluoretos de águas subterrâneas. Cabe destacar que neste estudo trabalhou-se apenas na investigação do carvão ativado de osso bovino para a remoção de íons fluoretos, não sendo comparado a sua eficiência com outros tipos de carvão ativado. Apesar disto, outros estudos (Campos e Veiga, 2006; WHO, 2006) têm destacado a alta eficiência do carvão ativado de osso como material adsorvente de íons fluoreto, quando comparado com outras tecnologias.

A capacidade de adsorção dos filtros, determinada para o primeiro ciclo de tratamento de cada um, apresentou resultados que flutuaram entre 475 e $3.480 \mathrm{mg} \mathrm{kg}^{-1}$ (Filtro $1=837 \mathrm{mg} \mathrm{kg}^{-1}$, Filtro $2=756 \mathrm{mg} \mathrm{kg}^{-1}$, Filtro $3=3.481 \mathrm{mg} \mathrm{kg}^{-1}$, Filtro $4=1.045 \mathrm{mg} \mathrm{kg}^{-1}$, Filtro $5=475 \mathrm{mgkg}^{-1}$ ). Esta flutuação nos resultados de capacidade de adsorção é resultante das diferentes condições de uso de cada sistema, cuja demanda de água (vazão do sistema e frequência de uso) é dependentes do usuário. Resultados similares de flutuação também foram obtidos pelos estudos de Costa et al. (2013), na confecção de filtros artesanais de desfluoretação, cujos resultados variaram entre 794 e $1.592 \mathrm{mg} \mathrm{kg}^{-1}$. 


\section{CONCLUSÃO}

Os resultados obtidos nesse estudo foram satisfatórios, pois os cinco filtros em operação apresentaram-se eficientes na remoção parcial de fluoreto, tratando em média $15.398 \pm 3.487$ litros de água (Coeficiente de Variação, CV=22,6\%), dentro do especificado pela portaria $n^{\circ} 2914$ (Brasil, 2011), a qual determina que a concentração de íons fluoretos na água para o consumo humano seja menor ou igual a $1,5 \mathrm{mg} \mathrm{L}^{-1}$. Desta forma, pode-se comprovar a alta eficiência do carvão ativado de osso na adsorção dos íons fluoretos da água, constatando que o sistema de desfluoretação pode ser aplicado como uso coletivo, tanto em escolas, universidades, casas e até mesmo em locais mais distantes dos grandes centros.

\section{AGRADECIMENTO}

Os autores agradecem à Coordenação de Aperfeiçoamento de Pessoal de Nível Superior (CAPES), ao Conselho Nacional de Desenvolvimento Científico e Tecnológico (CNPQ), à Fundação de Amparo à pesquisa do Estado do Rio Grande do Sul (FAPERGS) e à Universidade de Santa Cruz do Sul (UNISC).

\section{REFERÊNCIAS}

APHA, Ameican Public Health Association. Standard Methods: for the examination of water \& wastewater. 21 st. ed. Centennial Edition, 2005. 1238 p.

BONECHAR, Carvão Ativado do Brasil Ltda. Carvão ativado de osso. Disponível em: <http://www.bonechar.com.br/carvao-ativado>. Acesso em: 15 ago. 2016.

BRANCO, P de. M. Coisas que você deve saber sobre a água. 2016 Disponível em: $<$ http://www.cprm.gov.br/publique/Redes-Institucionais/Rede-de-Bibliotecas---RedeAmetista/Canal-Escola/Coisas-que-Voce-Deve-Saber-sobre-a-Agua-1084.html>. Acesso em: 20 ago. 2016.

BRASIL. Ministério da Saúde. Portaria $n^{\circ}$ 2914, de 12 de dezembro de 2011. Dispõe sobre os procedimentos de controle e de vigilância da qualidade da água para consumo humano e seu padrão de potabilidade. Diário Oficial União, Brasília, v. 239, p.39-46, 14 dez. 2011, Seção 1.

BUZALAF, M. A. R. Fluoretos e Saúde Bucal. São Paulo: Editora Santos, 2008.

CAMPOS, L. F. VEIGA, M. M. Desfluoretação parcial das águas de poços: uma aplicação do método de análise hierárquica/MAH. III Seminário Internacional de Engenharia de Saúde Pública, Fortaleza - Ceará, p. 44-54, 2006. Disponivel em: <http://bibliotecadigital.puccampinas.edu.br/services/e-books/sem3_vol2.pdf>. Acesso em: 24 mar. 2017.

COSTA, Adilson Ben et al,. Desfluoretação de águas subterrâneas utilizando filtros de carvão ativado de osso. Águas Subterrâneas, São Paulo, v. 27, n. 3, 2013. Disponível em: 
$<$ https://aguassubterraneas.abas.org/asubterraneas/article/viewFile/27382/17727>. Acesso em: 24 mai. 2017.

COSTA, A. B. et al., Avaliação da qualidade da água tratada por sistemas de filtração utilizando carvão ativado de osso. UNOPAR Científica Ciências Exatas e Tecnológicas, Londrina, v.7, p.5-12, nov. 2008. Disponível em: <http://www.pgsskroton.com.br/seer/index.php/exatas/article/view/692/663>. Acesso em: 24 mar. 2017.

FLORES, R. O. Fluorose Dentária, 2010 Disponível em: <http://www.ident.com.br/rodrigo_of/artigo/218-fluorose-dentaria>. Acesso em: 22 ago. 2016.

FREIRE, S. A.; EMMERICH, A. Flúor e Saúde Coletiva: 50 anos de fluoretação da água no Brasil. Universidade Federal do Espirito Santo, Editora Vitória. p. 186. 2003.

IBGE. Instituto Brasileiro de Geografia e Estatística, População do Brasil. Disponível em: <http://www.ibge.gov.br/apps/populacao/projecao/>. Acesso em: 10 ago. 2016.

KUMAR, E. et al. Defluoridation from aqueous solutions by nanoalumina: Characterization and sorption studies. Journal of Hazardous Materials, San Francisco, v.186, p.1042-1049, 2010

LOBO, E. A. COSTA, A. B.; KIRST, A. Qualidade das águas subterrâneas, em relação à concentração de íons fluoretos, na região do vale do Rio Pardo e Rio Taquari, RS, Brasil. Águas Subterrâneas, Fortaleza, XI Congresso Brasileiro de Águas Subterrâneas, p.1-15, 2000. Disponível em: <https://aguassubterraneas.abas.org/asubterraneas/article/view/24333/16337>. Acesso em: 24 mar. 2017.

MARIAPPAN, P. The studies on the Desfluridation of Water. Ph D Thesis, Alagappa University, Karaikudi. 630 003, 2001.

MURRAY, J. J. O uso correto de fluoretos na saúde pública. Organização Mundial da Saúde. São Paulo: Editora Santos, 1986 (edição brasileira de 1992).

PIRES, F. M.; BERND, B.; Ely, H.C.; PEGORARO, M. T. Flúor: manual informativo. Porto Alegre: Universidade Federal do Rio Grande do Sul, 1989.

RIBEIRO, M. V. Uso de Carvão de Osso Bovino na Desfluoretação de Água para Uso em Abastecimento Público, Belo Horizonte, 2011, p.1-75. Dissertação - (Programa de Pós Graduação em Engenharia Metalúrgica e de Minas - Mestrado e Doutorado). Universidade de Minas $\quad$ Gerais, 2011. Disponível em: <http://www.bibliotecadigital.ufmg.br/dspace/bitstream/handle/1843/CMBC8RZPRF/disserta_o_marcosviniciusribeiro.pdf?sequence=1 >. Acesso em: 24 mar. 2017.

WHO, World Health Organization. Fluoride in drinking-water. London, p. 134, 2006. 
Como citar este documento: PAPPIS, Cristiane et al. Monitoramento da qualidade da água tratada por sistema de desfluoretação de águas subterrâneas do campus da Universidade de Santa Cruz do Sul (UNISC), cidade de Santa Cruz do Sul, RS, Brasil. Revista Jovens Pesquisadores, Santa Cruz do Sul, v. 7, n. 1, jan. 2017. ISSN 2237-048X. Disponível em: 〈https://online.unisc.br/seer/index.php/jovenspesquisadores/article/view/9307>. Acesso em: ... doi: http://dx.doi.org/10.17058/rjp.v7i1.9307. 